Fecha de recepción: abril 2018

Fecha de aceptación: noviembre 2018

Versión final: diciembre 2020

\section{Geodesic Domes as Business Model in Hotel Management for Local Economies Development}

Theska Soares * and Amilton Arruda **

\begin{abstract}
This research aims to present the Buckminster Fuller geodesics in a contemporary context through a new hotel model, detailed by the case of the Ecocamp Hotel (CHILE), a pioneer in the construction of hotel rooms with geodetic domes incorporating aspects of local culture, sustainable development of the environment, and also, linking concepts of environmental awareness. This project was chosen for analysis because it was a great success, becoming a model for other ventures of the same segment, in other regions of the country, as well as abroad. It is important to show this case study because its model proves very promising also to be replicated in the context of the development of local economies in Brazil or in underdeveloped countries.
\end{abstract}

Key words: Geodesic domes - new business models - development of local economies sustainability.

[Abstracts in spanish and portuguese at pages 121-122]

${ }^{(*)}$ Theska Soares. She is a graduate, Master and $\mathrm{PhD}$ student in Design from the Federal University of Pernambuco (UFPE-BRA). She also majored in Product Design and Interior Design at Faculdade Boa Viagem (FBV-BRA) in partnership with the Istituto Europeo di Design (IEDBRA). During his professional career, he accumulated experience in several areas of Design, such as graphic design, fashion, packaging, web design, interiors, ergonomics and mainly industrial product design, where he focused on the creation and development of new products for the Tramontina industry using the methodology of Strategic Design. Currently she is a substitute professor in the Department of Design at the Federal University of Pernambuco on the Agreste campus (BRA), through the disciplines of Design History, Color Language and Three-Dimensional Representation System and also a researcher at the Biodesign Laboratory (UFPE / BRA) through research involving areas of Biomimetics and Strategic Design.

${ }^{(*)}$ Amilton José Vieira de Arruda. He holds a degree in Industrial Design from UFPE (1982), a Master's degree in Design and Bionics from the Ricerche Center of the European Design Institute of Milan (1992) and a PhD in Industrial Design from Politecnico di Milan (2002). He has been an international consultant for the Milan Institute of Design in the implementation of lato sensu postgraduate courses at Ávila (Goiânia) and FBV (Recife) and at the Institute of Higher Education in Brasília (DF). Since 1985, he is professor of the UFPE Design course. Professor of the post graduate Program in Design at UFPE. 
Coordinator of the research group Biodesign and Industrial Artifacts of CNPp. Has experience in the area of strategic design with emphasis on design and bionics, biomimetics, acting on our topics: product development, graphic design, editorial and strategic design. coordinator and editor with the publisher Blucher, of the [designCONTEXTO] series. arruda.amilton@gmail.com

\section{Introduction}

Krucken (2009) explains that countries with great diversity such as Brazil have a great wealth of cultures and ethnicities as well as biodiversity resources [...]. Encouraging the recognition of qualities and values related to the region - qualities related to the territory, resources, knowledge embedded in the elaboration of the tourism business strategy of experience and its importance to the local community - is a way of contributing to make visible to society the history behind the experience. Telling this "story" means communicating corresponding cultural and social elements, enabling the consumer to evaluate and appreciate it even more, collaborating with the valorization of the region. It means developing a favorable image of the territory in which the service originates. This visibility can contribute to the protection of cultural heritage and the diversity of cultures, thus being a factor in preserving cultural heritage, with a focus on the adoption and appreciation of sustainable practices, commercialization and even more conscious consumption.

In this context stands out the case of the hotel located within the Torres del Paine natural park (Patagonia-Chile) designed to promote ecological tourism with minimal impact on the surroundings. The choice of the geodesic configuration is very well associated with the idea of sustainability, since they are lighter structures, easy to assemble, saving materials and energy to heat, and that in fact, they are also a reference for the original indigenous huts of the region, which had the same hemispheric format, thus reinforcing aspects of local culture. The Geodesic Summits are emblematic structures patented by the American architect Buckminster Fuller, who gained a lot of visibility and became a symbol of modern architecture in the 1950s. According to the Buckminster Fuller Institute, there are more than 300,000 copies spread throughout the world, the EPCOT Center at Disney (USA). In the current context, many companies have recently observed the potential of using these structures in hotel projects linked to the concepts of sustainability and environmental awareness, such as the Ecocamp hotel in Patagonia (Chile), a pioneer in the construction of hotel rooms with geodetic domes.

The hotel is also an example of sustainable development of the environment, as it uses local suppliers to: purchase of food; horses used in transport; most of the furniture, crafts and decoration, and especially for the workforce, where $90 \%$ of the staff live in the area. There is also a shop with products from local partners of wool and leather, guaranteeing them a good monthly income. This case was so successful that it later became a model for other ecotourism ventures within Chile itself and in other European countries, which also raises the hypothesis of being an advantageous business model for the development of preservation areas in Brazil, including its vast coastal areas. 


\section{The Geodesic Domes}

In 1922, Bauersfeld, the German leading scientist of design for the optical industry Carl Zeiss, developed the first geodesic dome lined with cement to house a planetarium. But it was Buckminster Fuller who discovered the laws forming these structures, building and disseminating their properties in numerous optimization studies, thereby achieving patent no. 2,682,235 relating to the geodesic dome in 1954 and making it an icon of modern architecture, decade 50 (Forlani, 1983).

The geodesic domes are polyhedra with flat triangular faces (which also generate pentagons and hexagons) whose vertices coincide with the surface of an imaginary sphere that circumscribes it. Most of them are derived from the icosahedron (20 triangular faces), considered a geodetic sphere of frequency 1 . To generate different geodesic structures of the same diameter, simply increase the frequency, that is, subdivide the triangular faces into smaller and smaller triangles, the more higher the number of triangles in which its surface will be subdivided and the more its appearance becomes rounded.

For someone who does not know the story, a non-judgmental look at the geodesic domes might not clearly translate the concepts and inspiration behind these structures. As the form is too geometric and projected, this can lead to the misunderstanding that there is no relation to nature, but as it has been said, in fact, the relation exists.

Gorman (2005) reveals that in Explorations of Synergistic Geometry, from the 1940s, Fuller actually believed that he was investigating "the coordinate system of nature", inspired by the German naturalist Ernst Haeckel's Kunstformen der Natur and On growth and form by D'Arcy Thompson. In this way, the geodesic domes were inspired by the "macrocosm", considering the spherical celestial configurations, and in the "microcosm", considering the spherical microorganisms like those of Radiolaria. "Radiolarias are marine protozoa, whose species present the cytoplasm surrounded by a delicate central siliceous capsule, with perforations that let the pseudopods pass, simple or branchel” (Haeckel, 2005).

This class of protozoa living in marine plankton had its forms revealed in the studies illustrated in Haeckel's books that were first presented in 1904, the year of its first publication. Some of these radiolaries were represented by a series of radial skeletons that form geometric patterns, defining the reference and analogical bases of reference, analysis and conceptual application.

Not only Radiolarias, but he observed that several other natural structures also use the principle of leaky structures and spherical protective shell and container as observed in chapter 2. In this way, Fuller (1998) was convinced that the nature favors the spherical pattern and that this would be a representation of the coordinate system of nature, which triggered the study of mathematics for the engineering of this configuration.

Edmondson (2007), a Harvard professor who was a student of Fuller, reveals in Fuller's explanation: the synergetic geometry of R. Buckminster, that in fact, Fuller believed that a high-frequency geodetic polyhedron provides the true model of physical systems that is interpreted as spheres, since he did not agree with this notion of continuous surface equidistant from a central point as stated, for example, in soap bubbles, for him this definition was scientifically unacceptable and inconsistent with physical reality, as it justified that 
in some levels of resolution, all "spheres" consist of an incalculable number of energetic events interconnected by an even greater number of vector relations or forces. Fuller (1979) himself explains how these mistaken spherical sensations are produced:

Because of the matrices of polyhedral interferences identified as points very nearly equidistant from a central point and because the mass-attractive or mass-repulsive relations of all points between them are more economically manifested by strings and not arcs ... the matrix spherical is actually produced by points of omnitriangulated geodesic structures of very high frequency.

Indeed, the eyes cannot see individual molecules in the transparency of a soap bubble, nor can the chemical attractions be detected between molecules through these strings identified by Fuller (at least not so far), however, such connections exist, the which makes its theory coherent.

According to Soares (2016), the American Institute of Architects (AIA) has designated the geodesic dome as "the strongest, lightest and most efficient means of including space known to man". Verschleisser (2008) also reveals that the geodesic domes have self-support with extraordinary resistance and lightness due to their spherical shape and the geometric forms that constitute them, they communicate and support each other creating a system called Fuller tensegrity integral), in which any force applied in one of them retransmits the tension and distributes it equally between the others to its base, as well as the arcs in the engineering. Moreover, much of this structural advantage comes from the enormous stability provided by its triangular mesh. A triangle is a stable element independent of its size; they are the only shapes that remain rigid, even when constructed with flexible connections, with each vertex stabilizing on the opposite side. When forces generate a stabilized form, that is, able to sustain itself, they create a Structure. In his book Synergetics, Fuller (1979) states that the triangle is the only self-stabilizing polygon and that everything that is recognizable in the Universe as a Pattern is identifiable as previously seen, and the triangle persists as a constant pattern. Any other known patterns are inherently recognizable only by the virtue of their triangular structural integrity, where structure means an omnitriangulation. Only triangular structured patterns are regenerative patterns, and triangular structuring is a standard of integrity in and of itself.

One of the ways Fuller (1979) describes force strength between a rectangle and a triangle would be to apply pressure to both structures. The rectangle bends over its vertices and would be unstable, but the triangle resists pressure and is about twice as strong and stiffer. This principle guided his studies to the creation of the geodesic dome, in which he discovered that if a spherical structure were created from triangles, it would have an unequaled strength.

Thus, polyhedra formed entirely by regular triangular faces correspond to the more selfstabilized structures, and therefore are the most indicated and used by Fuller in the geodesic configurations, since other geometries such as squares, pentagons, hexagons, by the inherent tendency the deformation at its vertices are more unstable, so the spherical solids derived from meshes other than the triangular need to be rearranged within a triangular logic or distributed together with it for more resistance (Pearce, 1980). 
The triangle is a natural mathematical figure that, in combination with other triangles, provides maximum efficiency with minimal structural effort. By bringing together a series of identical geometric units that are self-sustaining and lightweight, Fuller has obtained a dynamic construction in which the individual components contribute to the overall structure, and it is no wonder that such a system is so used by engineering, in tetrahedral applications, for example in the roofs of large sheds; or in non-apparent applications, such as in beams.

Another geometrical advantage of these structures refers to the spherical configuration itself. Fuller (1979) emphasizes the idea that when the diameter of the sphere is doubled, its area will quadruple and expand by eight times the volume. Naturally the spheres perfectly match the principle of "doing more with less" because they include the largest volume with the least amount of surface area in the domes, this immediately reflects a material saving guarantee. In addition, the spherical structure of a dome is one of the most efficient indoor atmospheres for human dwellings, because air and energy can circulate without obstruction, allowing both heating and cooling to occur naturally.

Still in relation to the specific configuration of the geodesics, there is also a considerable advantage in the five or six bars coming out of each vertex: forces are instantaneously distributed in many directions omniradially, reason why, they produce an unprecedented force with respect to their weight (Edmondson, 2007).

Fuller's objective with these eccentric constructions was to create versatile, cheap, energy efficient, lightweight and flexible shelters: living machines, capable of being modified according to the needs of those who inhabited them and is what seems to be happening through the rescue of these structures for various purposes today.

\section{The business model of the Ecocamp Hotel}

The Ecocamp is a hotel located inside a natural park in Patagonia (Chile) with a privileged view to the mountainous region Torres del Paine. Founded in 2001 by the engineers and owners of the Cascada Expediciones (adventure tour company) Javier Lopez, Yerko Ivelic and Nani Astorga, was the pioneer in building hotel rooms with geodesic domes based on Fuller's derived model, although the hemispherical shape is also an indigenous hut of the region.

Similar as in the traditional hotels that have several options of rooms, in the Ecocamp there are 4 options of domes for lodging: Standard with 10sqm, Suite with 28sqm, Loft with $37 \mathrm{sqm}$ and Superior with $23 \mathrm{sqm}$. The dining venues, yoga classes, shop and bar are community geodesic domes that provide a meeting place where guests can share stories with each other and plan future excursions.

Parameters of Ergonomics of the built environment such as: thermal, acoustic and luminous comfort; accessibility and environmental perception will be presented below; as well as the sustainable aspects of the hotel that address the current trends and urgencies will be addressed. The purpose of these analyzes is to facilitate the visualization and understanding of the context in which the applications of constructions with geodesics generally fit. 
Starting with the thermal, acoustic and luminous aspects of comfort, it can be said that the geometry of the geodesics favors an improved flow of air, the concentration of light and heat and a more uniform temperature than in a conventional dwelling. The surface area exposed on the outside in the domes is also smaller, allowing less heat exchange with the environment; In addition to this, the volume of air inside the dome is also smaller, which translates into economy to keep you cool in the winter, saving up to 50\% in energy to heat. The excellent distribution of the airflow inside the domes further avoids areas of air stagnation and, therefore, there is a proliferation of fungi, bacteria and moisture.

The translucent areas of the roof of the domes naturally make them excellent collectors of solar energy, reflecting the light and heat into the structure as a greenhouse, avoiding the loss of heat by irradiation. This situation becomes very useful for regions with severe winter as in Patagonia, allowing even without masonry walls, with the help of the wood burning fireplace, solar heating, and the apparent structure of galvanized iron with the outer cover of green tarpaulin and transparent, plus an inner layer of insulation pad are efficiently sufficient to ensure heat and protection from the strong and cold winds of the place. Combined with this, thermal comfort is also guaranteed by a gas system for heating the water. On the acoustic comfort, Lotufo (1981) also emphasizes the acoustic quality provided inside the domes, the geometry favors that the sound is reverberated within them and that it becomes a barrier for the sounds from outside. In the case of the hotel, this quality can be used within the domes for social interaction with musical performances and privacy can be guaranteed with the distance given between these domes. Being in a region of strong winds, the format helps to reduce the external noise a bit, although still allowing the sounds of nature to be used, which is a positive point.

Already the lighting of the hotel privileges natural light for most of the day. Inside the domes there are skylights that facilitate the capture of daylight and at night there is the illumination by lamps and led torches from the green energy solar capturing. It is enough, but a negative point is that in the version of the Standard dome is necessary to request flashlights because the lighting is non-existent, getting compromised in other areas of the hotel on strict winter days when solar illumination is precarious, even with electric generator.

Regarding accessibility, although the hotel's proposal is clearly aimed at an active public seeking adventure, sportsmanship, which is evidenced by the programs of activities available at the hotel such as walking, cycling or horseback riding on uneven terrain, peaks, bridges or even yoga, canoeing, it is also important to discuss the ease of movement between the built environment of the hotel, for people with mobility difficulties, such as wheelchair users and the elderly. Here, this becomes a negative point, as there are no ramps and as the constructions are suspended, even by relatively low wooden platforms, there are always stairs and stops making passage difficult. The Standard version with only 10sqm is also not suitable for wheelchairs, although in other areas, the fact that the domes are larger and free of internal walls contributes to an unobstructed movement. Seniors may also feel discouraged to stay in the domes furthest from community areas as they would have to take long walks to and fro, though for some this may not be an exclusionary problem. Regarding this accessibility for people with visual impairments, these would also feel certain difficulties because of the stops and stairs, but also would not be a total impediment, 
especially if they are accompanied. The hearing impaired would have no problems with the hotel's surroundings, since they are very intuitive with the wooden walkways connecting all the domes, but they may feel difficult to communicate if they are unaccompanied and there is no hotel person capable of speaking of signs, yet nothing that a notepad does not help.

However, a positive point of the hotel refers to accessibility more comprehensively, worrying about the surrounding environment, and this can be observed in planning the construction of the domes on raised platforms and in the absence of fences around the Ecocamp, which allows that the passage of animals under the structures is not blocked and that horses and other animals of the park can enter freely. Solar lamps illuminate the catwalks and domes at night, being very subtle, so as not to disturb the nocturnal animals so that they do not feel threatened by the hotel. Not only thinking about the accessibility of man in the design of the built environment, but also that of the animals that live in the place remains an innovative approach, according to current trends of environmental concern. On environmental perception, the domes offer a very different and attractive look to the layout of the hotel and the radial pattern allows the creation of more sociable spaces. With self-supporting roofs, it is possible to have ample unobstructed spaces without the need for beams, columns or support walls inside, and this tends to approach rather than separate people. Another pertinent perception is that psychologically the concave curvature inside the dome is more welcoming than the flat ceiling.

All sleeping domes are comfortable, even the smaller version, Standard, in which the bathroom is shared and has no heating system or lighting. The other versions have a spacious area for beds, a fireplace, private bathroom, gas water heating and electric power for cell phones and laptops, but a negative point for some is the fact that there is no Wi-Fi available (only in communal areas), or dryers, since the energy consumption is limited and the goal is to have a more natural experience possible within what is possible in terms of comfort of interaction with nature, since everything is thought so that one notices the premise of the hotel concern and environmental responsibility.

The social aspect is one of its most celebrated attributes, which promotes activities, walks in groups and stimulates the conviviality. There are four domes for community use, they are attached to the other sleeping domes by hanging wooden walkways. One is the cafeteria where everyone eats together, the other a bar / lounge, a third is dedicated to yoga and the last one contains a shop and a small library. In them, guests can interact, sit, read, talk, do yoga, enjoy the good gastronomy of the hotel, relax, share their stories and adventures of the day, etc. Guides usually also use the community library dome to show guests trail maps and wildlife viewing points. All community domes are surrounded by terraces, with ample room to favor social interaction.

Despite having a different configuration from the usual, the domes are very well seen by the visitors that show the original design inside beautiful geometric forms, besides the approval of the idea of green hotel. In 2016, its facebook page has reached more than 20,000 tannings and an approval of almost 5 stars, same approval on Tripadvisor's website with almost 500 comments from guests satisfied with their experiences, whose packages range from \$ 2600 to $\$ 5300$ dollars, (including: activities, hotel, meals and transfers). 


\section{Geodesic Domes: Portable and Economical Design}

The geodesic dome shape is very advantageous, because it optimizes the load, displacing the forces throughout its structure, for this it is ergonomic, aerodynamic and strong to withstand extreme situations like: strong winds, storms, earthquakes and accumulation of snow. The stronger the wind, not having suction surfaces, surrounds it and says more on the ground, including in the region of the hotel the speed of the winds can reach $200 \mathrm{~km}$ / h. In addition, the sphere has $25 \%$ less surface area per closed volume than any other shape. The dome combines the inherent stability of the triangles with the advantageous volume / surface area ratio of a sphere which results in less building materials to include more space. There is an estimated 30\% reduction in materials and 50\% energy compared to a conventional masonry construction of the same built area. It also reduces labor costs, since assembly and maintenance is easier, simpler and faster.

Having less material, less surface area, no internal walls and composed of lighter materials than masonry, such as galvanized iron pipes, tarpaulins, insulation pads and wood, this portable design does not need a complicated foundation, in the case of the Ecocamp a hanging platform of pine was enough, this facilitated that in 2005 the hotel changed of place, going to the foot of the Towers without leaving vestiges in the previous place. Being easy to mount, it is well suited even to remote places like there, but it is also for deserts, poles, forests, beaches, mountains, etc. Another interesting observation about the visual composition of the hotel is that by the domes being green, the platforms of wood and of limited height, camouflam harmoniously in the natural landscape.

\section{The Ecocamp Hotel and its aspects of Sustainability}

In 2008, it became a company with carbon-free certificate. This certificate is possible for companies aiming to minimize $\mathrm{CO}^{2}$ emissions as much as possible. The estimate is that in 1 year hotel policies offset some 230,000 tonnes of $\mathrm{CO}^{2}$ emissions. Buying from local suppliers also avoids issuance by transport, since other hotels in the region receive deliveries on flights from the capital or abroad. And as they offer adventure expeditions, the means of transport that they provide are also free of emission, such as horses, bicycles, canoes and legs for hiking on the trails, being necessary the use of cars only for the arrival and departure of the guests.

All electrical energy from the hotel comes from water turbines and photovoltaic panels, that is, obtaining energy from $100 \%$ renewable sources, being $40 \%$ solar, since it is very efficient in the summer, when Patagonia receives up to 17 hours of sunshine per day, and $60 \%$ hydro. The capture of energy by the water turbines is done by $51 / \mathrm{s}$ of river water that pass through the turbines delivering a constant power of 800 Watts. An inverter is used to switch batteries from $24 \mathrm{~V}$ to $220 \mathrm{~V}$, the standard voltage in Chile. Allied to this, an array of 1700 photovoltaic panels also connected to the battery bank complete the amount of energy required for the operation of the Ecocamp hotel.

Thus, these batteries power all refrigerators, lighting, appliances, stereos, etc. Propane gas is only used to heat the water and the upper cupolas, but there is a pilot project to heat 
the shower water also with solar energy. With the hotel's energy-saving policy, it is limited and is only available for guests to carry their gadgets, and it is not possible to use it for hair dryers or shavers, for example.

The implementation and maintenance of this whole sustainable structure is a direct work of the owners and engineers Javier and Yerko. They not only designed the whole concept, but also taught, qualified, and supervised a whole team to maintain these resources.

In addition, the hotel has waste management that aims to reduce paper, cans and plastic waste to the maximum, until the suppliers are chosen with great care, ensuring that they are aware of complying with the environmental standards of the hotel that seeks to buy in bulk, so as to limit individual packaging to a minimum to be brought into the park. All waste is separated according to the recycling status: organic, paper, glass and hazardous or toxic materials. The nonorganic are removed and shipped to the nearest town of Punta Arenas for recycling, and the organic material serves as pig feed on a nearby farm.

Guides take care to prevent guests from throwing rubbish on the routes while hiking, bringing back all non-biodegradable material back to the hotel. There are re-use of the lunch zip-lock and water bottles and there is a manual at all domes informing ecological practices which include: standing on the wooden walkways, not smoking inside the domes, using biodegradable hygiene products, not discarding batteries, minimize time in the shower and share the transport.

And it also works with the most modern composting device in the world, being the first in the hotel industry throughout Chile and Patagonia. The chambers collect waste from the toilets and separate the solid material from the liquid. The solid is mixed with paper and wood chips and receives heat to keep microorganisms alive and the composting process active. Already the liquid material passes through the cleaning chamber where it is filtered, then passed to earth. Due to the low temperatures in Patagonia, there is a great effort to maintain this process.

\section{The Ecocamp Hotel and the development of the local economy}

Thinking about sustainable development of the environment, the most logical social support the hotel can offer is to buy locally and employ local residents, guaranteeing them a good monthly income. For this reason, even horses are hired from nearby farmers, most of the furniture, crafts and decoration are also from Punta Arenas and all food is bought from the region (eggs, meats, fish, cheeses, dried fruits, grains, marmalade, breads, fruits and vegetables). In addition, it also has a store that sells clothing from local producers, mainly wool and leather.

About $90 \%$ of all employees are from the local region, most of them from Puerto Natales and Punta Arenas, including specialized guides who grew up in the region and studied at ecotourism universities in areas such as geology, ornithology and botany. The owners and the manager are from Santiago. All live an eco-friendly life, taking care of energy, water and waste management. They share the environmentally sustainable philosophy over the years and encourage their customers, suppliers and shareholders to think and act in the same way. It also fosters this understanding of the importance of nature among neighbors, 
sharing their strategies and sustainable innovations with the region's development body to help other entrepreneurs follow the same path.

\section{Conclusion}

To use the geodesics as an innovative business model in hotels that have been shown more coherent for the sustainability that is urgent and that can be replicated in other regions of preservation, both in Brazil and in other places of the world. Energy from renewable sources, domes that maximize heat and solar lighting, walkways designed to minimize disruption of the land to the environment, toilets with composting devices, minimization of waste and waste, environmental respect, social responsibility, a whole strategy of designed to create spaces where travelers can connect with nature and explore Torres del Paine minimizing the impact on the environment, it is even a path full of possibilities to be explored and undoubtedly, essential and of utmost importance for it to be replicated in other places in conditions of preservation or that uses the business model that promotes regional development.

And it is this thinking projectual making that should be brought to the discussion. It is necessary to understand the design of spaces in the various dimensions that surround it, attending them equally to the extent that they will interfere in the future performance of the project and even more so in the future of humanity. It is necessary to expand horizons, not only to stick to the functionality of spaces, usability and accessibility and think not only of segments perfectly harmonized with the man who inhabits and lives the environments, but go beyond and think also in their surroundings, bring to the take up these new issues and assume that in this way man can collaborate with a larger whole, where the benefits are more comprehensive.

In this sense, Ecocamp Hotel has proven itself a great example, being a leader in environmentally responsible travel, seeking to minimize the impact of each visitor in Torres del Paine National Park and is constantly studying, testing, buying and installing sustainable technologies for green energy supply and waste management, with the premise of bringing comfort to the limits of only what is sustainable, resisting the concept of luxury that so many other hotels aspire to, because environmental conservation is a priority over any practices that could be detrimental to the park, and this is a very interesting point of view, because to protect the park is to be responsible in a broader way, is to be worried about the future of the next generations.

The summits and all the vision behind EcoCamp Hotel is admirable, other companies have used this example as a basic design for other business models in hotels such as Punta de Domos, Magma Lodge and Elqui Domos in Chile; as well as Whitepod (Switzerland) and Aurora Dome (Finland) in Europe. With this, it is concluded that this model has many arguments to be replicated in a similar way for the development of regional in Brazil, both coastal regions, with its vast and exuberant beaches, as well as the interior, through the great potential of application to the sustainable tourism of environmental preservation regions such as the Pantanal, the Amazon, Foz do Iguaçu, Chapada Diamantina, among many other areas of natural beauty in the country. 
Still, other parts of the world could follow your example and use the hotel model to contribute ideas and values for the preservation of Earth's natural resources through these strategies because caring for the environment is as important as it is promising to inspire tomorrow's tourism.

\section{References}

Edmondson, A. C. (2007). A Fuller explanation: the synergetic geometry of R. Buckminster Fuller. Pueblo: EmergentWorld.

Forlani, M. C. (1983). Materiali Strutture Forme. Firenze: Alinea.

Fuller, R. B. (1998). Manual de instruções para a nave espacial Terra. Porto: Via Optima.

Fuller, R. B. (1979). Synergetics 2: Further explorations in the geometry of thinking. New York: Macmilian.

Gorman, J. M. (2005). Buckminster Fuller: Designing for mobility. Milano: Skira Editore S.p.A.

Krucken, L. (2009). Design e Território: Valorização de Identidade e Produtos Locais. São Paulo: Studio Nobel.

Haeckel, E. (2005). Art Forms from the Ocean. New York: Prestel.

Lotufo, V. A.; Lopes, J. M. A. (1981). Geodésicas \& Cia, $1^{\text {a }}$ ed. São Paulo: Projeto Editores Associados Ltda.

Pearce, P. (1980). Structure in Nature is a Strategy for Design. Massachusetts: The MIT Press.

Soares, T. A. (2016). Biomimética e a Geodésica de Buckminster Fuller: Uma Estratégia de Biodesign. Dissertação (mestrado) - Universidade Federal de Pernambuco, Recife, Departamento de Design do Centro de Artes de Comunicação.

Soares, T.; Arruda, A. (2016). As estruturas Geodésicas do Ecocamp na Patagônia: Um estudo sobre seus aspectos ergonômicos e Sustentáveis. In: $1^{\circ}$ Congresso Internacional de Ergonomia Aplicada, 2016, Recife. Blucher Engineering Proceedings. São Paulo: Editora Blucher. V3. pp. 216-227.

Soares, T.; Arruda, A.; Hartkoff, C.; Barbosa, J.; Balestra, R. A. (2016). Relação entre a Biomimética e a Geodésica de Buckminster Fuller no Planejamneto de Construções Sustentáveis. $7^{\circ}$ Congresso Luso Brasileiro para o Planejamento Urbano, Regional, Integrado e Sustentável. Maceió.

Verschleisser, R. (2008). Aplicação de Estruturas de Bambu no Design de Objetos. Como Construir Objetos Leves, Resistentes, Ecológicos, e de Baixo Custo, Tese (Doutorado). Rio de Janeiro: Pontifícia Universidade Católica do Rio de Janeiro.

Resumen: Esta investigación tiene como objetivo presentar las cúpulas geodésicas de Buckminster Fuller en un contexto contemporáneo a través del caso del Hotel Ecocamp (CHILE), un pionero en la construcción de habitaciones de hotel con cúpulas geodésicas incorporando aspectos de la cultura local, desarrollo sostenible y conceptos de conciencia ambiental. Este proyecto fue elegido para el análisis porque fue un gran éxito, convirtiéndose en un modelo para otras empresas del mismo segmento, en otras regiones del país, 
así como en el extranjero. Es importante mostrar este estudio de caso porque su modelo resulta muy prometedor y también se puede replicar en el contexto del desarrollo de las economías locales en Brasil o en los países subdesarrollados.

Palabras clave: cúpulas geodésicas - nuevos modelos de negocios - desarrollo de economías locales - sostenibilidad.

Resumo: Esta pesquisa tem como objetivo apresentar as cúpulas geodésicas de Buckminster Fuller num contexto contemporâneo através do caso do Ecocamp Hotel (CHILE), pioneiro na construção de quartos de hotel com cúpulas geodésicas que incorporam aspectos da cultura local, desenvolvimento sustentável e conceitos de consciência ambiental. Este projeto foi escolhido para análise porque foi um grande sucesso, tornando-se um modelo para outras empresas no mesmo segmento, em outras regiões do país, bem como no exterior. É importante mostrar este estudo de caso porque seu modelo é muito promissor e também pode ser replicado no contexto do desenvolvimento das economias locais no Brasil ou em países subdesenvolvidos.

Palavras chave: cúpulas geodésicas - novos modelos de negócios - desenvolvimento de economias locais - sustentabilidade. 